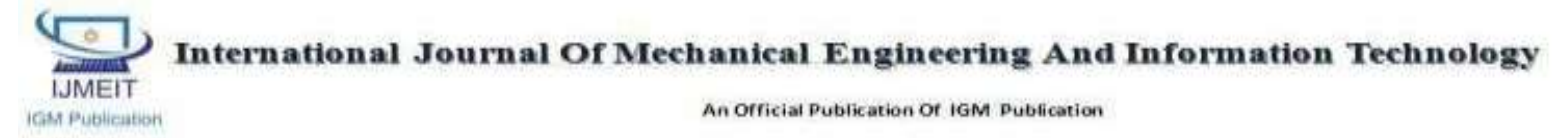

\title{
Casting of Hypoid Gear \& Process Cost Reduction
}

\author{
Authors \\ Akash Bharadwaj ${ }^{1}$, Sanjeev ${ }^{2}$, Harinada Rao \\ ${ }^{1}$ M.Tech Department of Mechanical Engineering CBS Group of Institution Jhajjar, Haryana \\ ${ }^{2}$ Guide- Assistant Professor Department of Mechanical Engineering CBS Group of Institution Jhajjar, \\ ${ }^{3}$ Guide- M.Tech Senior Engineer (Spicer India Pvt. Limited) \\ Email- akashgistmech@gmail.com
}

\begin{abstract}
This is the project that implementation of Casting of Hypoid Gear in Gear Plant at Spicer India Pvt ltd. My purpose for this project elimination of Hobbing or Milling operation use for gear teeth cutting \& saving the manufacturing cost of some process.

This gear is use in differential of Rear axle of Automobile vehicle (LMV Vehicle), due to passenger use vehicle we require high quality and budget cost. We plan to develop casting with gear teeth not only Blank, because in forging we made blank forge part then we do Semi finish, Finish, Rolling, Taping, Hobbing or Milling, Heat treatment, Grinding, Lapping etc.

If we can true my thesis of gear teeth manufacturing with casting then we can hide Gear teeth cutting process, due to this objective we can increase our capacity \& save our process cost 10 lakhs/ month.

I follow several step for my thesis validation, firstly designing of core, mould then I will do casting and more test as crack test (MPI \& Ultra sonic testing).
\end{abstract}

\section{INTRODUCTION}

A gear is a component with in a transmission device that transmits rotational force to another gear or device. A gear is different from a pulley in that a gear is a round wheel which has linkages ("teeth" or "cogs") that mesh with other gear teeth, allowing force to be fully transferred without slippage. Depending on their construction and arrangement, geared devices can transmit forces at different speeds, torques, or in a different, from the power source. Gears are a very useful for simple machine.

The most common situation is for a gear to mesh with another gear, but a gear can mesh with any device having compatible teeth, such as other rotational gears, or linear moving racks. A gear's most important feature is that gears of unequal sizes (diameters) can be combined to produce a mechanical advantages, so that the rotational speed and torque of the second gear are different from that of the first. The smaller gear in a pair is often called the pinion; the larger, either the gear, or the wheel shown in fig 1.1

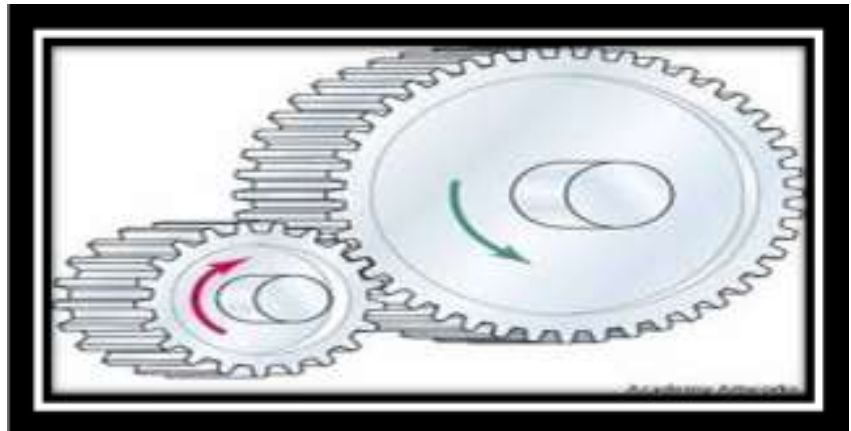

Fig 1.1

Different Types of Gears:

1.1.1 Spur gears:

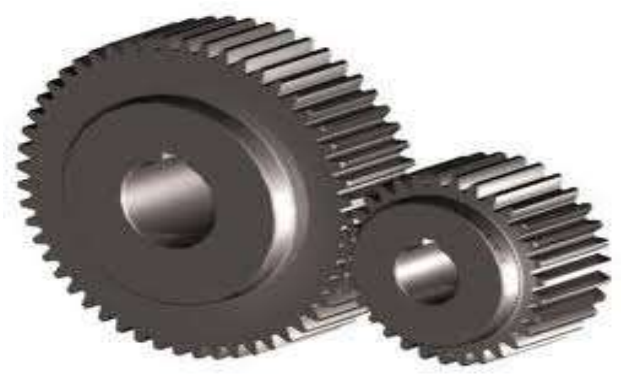

Fig 1.2 shows setting of spur arrangement. 
Spur gears are the simplest, and probably most common, type of gear. Their general form is a cylinder or disk (a disk is just a short cylinder). The teeth project radially, and with these "straight cut gears", the leading edges of the teeth are aligned parallel to the axis of rotation. These gears can only mesh correctly if they are fitted to parallel axles.

\subsubsection{Helical gears:}

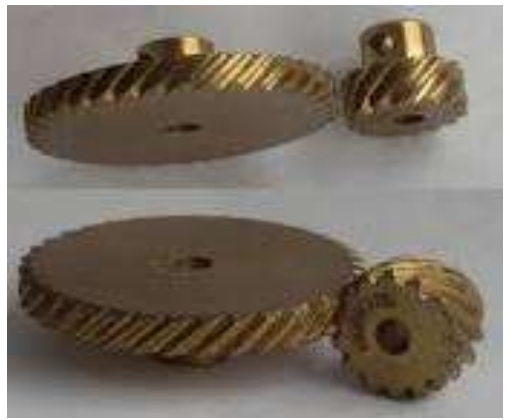

Fig 1.3 describes about helical gears.

Helical gears offer a refinement over spur gears. The leading edges of the teeth are not parallel to the axis of rotation, but are set at an angle. Since the gear is curved, this angle causes the tooth shape to be a segment of a helix. The angled teeth engage more gradually than do spur gear teeth. This causes helical gears to run more smoothly and quietly than spur gears. Helical gear also offer the possibility of using non-parallel shafts. A pair of helical gears can be meshed in two ways with shafts oriented at either the sum or the difference of the helix angles of the gears.

\subsubsection{Bevel gears}

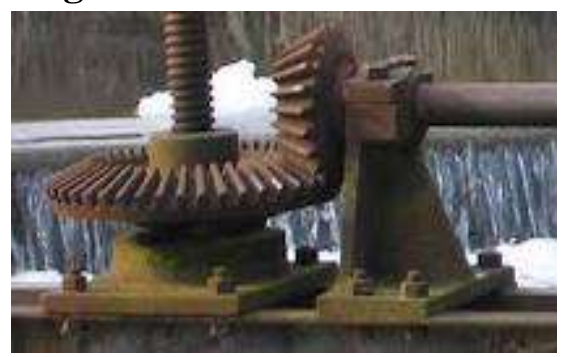

Fig 1.4 Bevel gears arrangement is shown Bevel gears are essentially conically shaped, although the actual gear does not extend all the way to the vertex (tip) of the cone that bound it. With two bevel gears in mesh, the vertices of their two cones lie on a single point, and the shaft axes also intersect at that shafts can be anything except zero or 180 degrees. Bevel gears with equal numbers of teeth and shafts axes at 90 degrees are called miter gears.
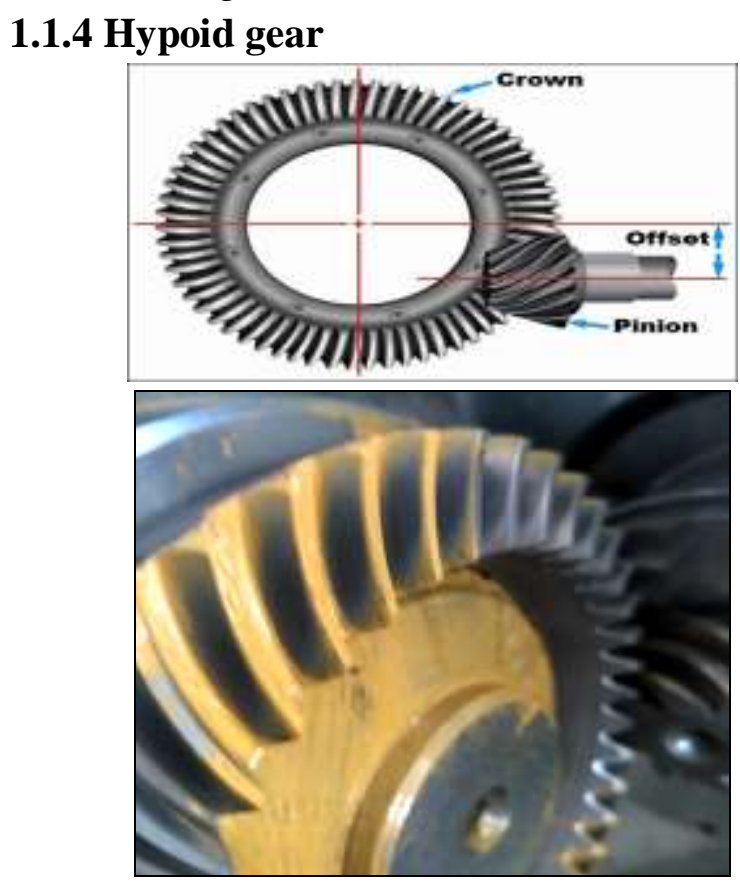

Fig 1.5 A Hypoid gear

A Hypoid gear or contrite gear is particular forms of gear whose teeth project at right angles to the plane of the wheel in their orientation the teeth resemble the points on a Hypoid. A Hypoid gear can only mesh accurately with another bevel gear, although Hypoid

Gears are sometimes seen meshing with spur gears. A Hypoid gear is also sometimes meshed with an escapement such as found in mechanical clocks. Hypoid gear develop from Bevel Gear for one \& only Differential purpose in Automobile vehicle axle. Difference between bevel gear \& hypoid gear are:-

Hypoid gear always mesh above center or below center but bevel gear mesh on center.

Bevel gear pressure angle is fixed but Hypoid gear pressure angle should be design as we required.

\subsubsection{Worm gear:}

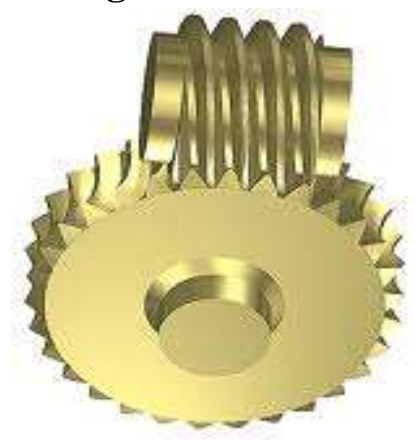

Fig 1.6 shows worm gears arrangement. 
A worm is gear that resembles a screw. It is a species of helical gear, but its helix angle is usually somewhat large (i.e. somewhat close to 90 degrees) and its body is usually fairly long in the axial direction; and it is these attributes which give it its screw like qualities.

A worm is usually meshed with an ordinary looking, disk-shaped gear, which is called the "gear", the "wheel", the "worm gear", or the "worm wheel". The prime feature of a worm-andgear set is that it allows the attainment of a high gear ratio with few parts, in a small space.

\subsubsection{Rack and pinion}

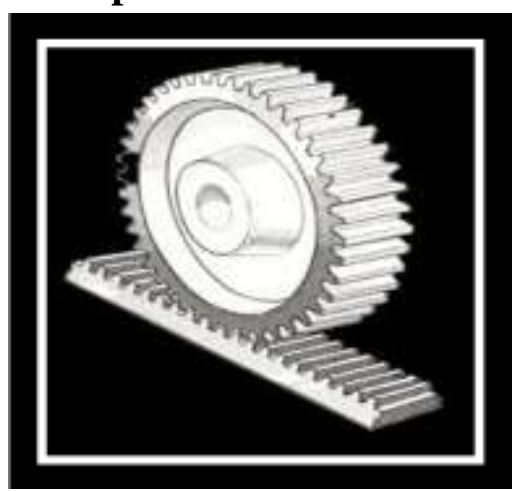

Fig 1.7 shows rack and pinion

A rack is a toothed bar or rod that can be thought of as a sector gear with an infinitely large radius of curvature. Torque can be converted to linear force by meshing a rack with a pinion: the pinion turns; the rack moves in a straight line. Such a mechanism is used in automobiles to convert the rotation of the steering wheel into the left-to-right motion of the tie rod(s). Racks also feature in the theory of gear geometry, where, for instance, the tooth shape of an interchangeable set of gears may be specified for the rack (infinite radius), and the tooth shapes for gears of particular actual radii then derived from that.

\subsection{Gear nomenclature}

Path of contact: The path followed by the point of contact between two meshing gear teeth.

Axis: The axis of revolution of the gear; center line of the shaft.

Pitch point (p): The point where the line of action crosses a line joining the two gear axes.

Pitch circle: A circle, centered on and perpendicular to the axis, and passing through the pitch point. Sometimes also called the 'pitch line'. Although it is a circle.

Pitch diameter (D): Diameter of a pitch circle. Equal to twice the perpendicular distance from the axis to the pitch point. The nominal gear size is usually the pitch diameter.

Operating pitch diameters: The pitch diameters determined from the number of teeth and the center distance at which gears operate. ${ }^{2}$ Example for pinion: $d_{w}=\frac{2 a}{u+1}=\frac{2 a}{\frac{2 a}{z_{1}}+1}$

Angle of action: Angle with vertex at the gear center, one leg on the point where mating teeth first make contact, the other leg on the point where they disengage.

Arc of action: The segment of a pitch circle subtended by the angle of action.

Outside diameter $\left(\boldsymbol{D}_{0}\right)$ : Diameter of the gear, measured from the tops of the teeth.

Root diameter: Diameter of the gear, measured from the base of the tooth space.

Addendum (a): The radial distance from the pitch surface to the outermost point of the tooth.

$$
\mathrm{a}=\left(D_{0}-\mathrm{D}\right) / 2 \text {. }
$$

Dedendum (b): The radial distance from the depth of the tooth through to the pitch surface. $\mathrm{b}=(\mathrm{D}-$ root diameter $) / 2$.

Whole depth $\left(\boldsymbol{h}_{\boldsymbol{t}}\right)$ : Whole depth (tooth depth) is the total depth of a tooth space, equal to addendum plus debendum, also equal to working depth plus clearance.

Clearance: Clearance is the distance between the root circle of a gear and the addendum circle of its mate. Hypoid pinion nomenclature shown in fig 1.9

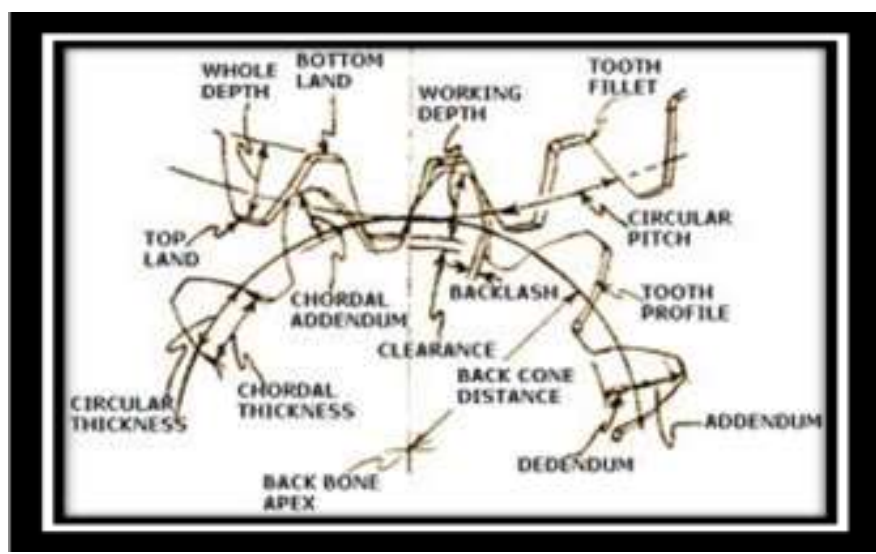

Fig 1.9 
Working depth: Working depth of engagement of two gears, that is the sum of their operating addendums. ${ }^{2}$

Circular pitch (p): The distance from one face of a tooth to the corresponding face of an adjacent tooth on the same gear, measured along the pitch circle.

Diametral pitch $\left(P_{d}\right)$ : The ratio of the number of teeth to the pitch diameter. Eg. Could be measured in teeth per inch or teeth per centimeter.

\section{PREPARATION OF HYPOID PINION MOULD CAVITY}

Patterns are developed as per the drawings provided by the customers or can be developed on the basis of requirements of our products. Pattern is replica of the product and it is used for preparing hollow cavity of original product for pouring molten metal. Here in case of Hypoid pinion we make mould cavity of pinion by core setting method for reducing the pattern making cost.

\subsection{The following are the steps involved in core setting method}

3.1.1. Template making: template is a wooden plate of thickness $15 \mathrm{~mm}$ is forming as shape of Hypoid pinion front view adding contracting allowance and machining allowance. This is used as guide plate for setting cores.

The model of Hypoid pinion template is shown in below fig 3.1

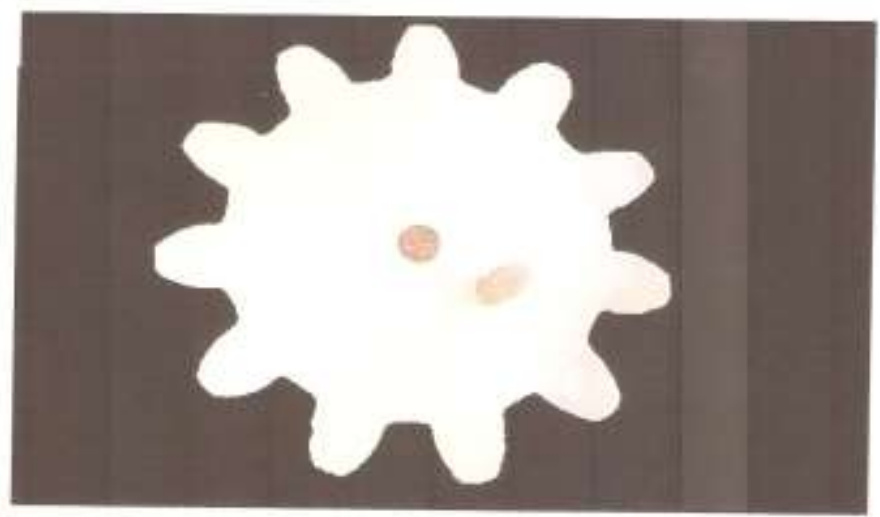

3.1.2. Cores making: Core is a predetermined shaped mass of sand which is made separately from mould. It is positioned in a mould to obtain a shape in the casting which can not be readily obtained by the mould proper. We need a core box making cores, generally it is made by wood. The main purpose of core is to obtain the desired cavities and recesses which other wise could not be obtained by normal moulding operation. For making cores a recent development is to mix sand with sodium silicate solution so that the grains are coated and obtain the necessary hardness by "gassing" with carbon dioxide, causing the sodium silicate to bond the grains together and produces strong core.

3.1.2.1. Making of cores for the gap between two consecutive teeth's:

In this process first we make a core box for the hollow part between two consequent teeth's of Hypoid pinion with some back extension for support. By using this core box we can make number of sand cores with $\mathrm{CO}_{2}$ moulding process as per requirement. Here incase of this pinion we need eighteen cores because this pinion has eighteen tooth.

3.1.2.2. Making of center core.

A center core is required to produce center hole of Hypoid pinion. This core is made separately in a core box made by wood.

\subsection{Cores are made by hand moulding by $\mathrm{CO}_{2}$ Process:}

Core making is by $\mathrm{CO}_{2}$ and no-bake process. Chrome Ore Sand and Zircon Sand is used for core moulding. Most of the moulds are coated with Zircon refractory coating to give excellent surface finish. Now a day this process has been adopted in several countries because of rapid hardening of sand. It consists of thorough mixing of silica sand (clean, dry and free from clay) with $3.5 \%$ to $5 \%$ by weight of sodium silicate liquid base binder in amiller. Sometimes coal - dust, saw dust are also added so as to improve the collapsibility property. The mixture is then put into core-boxes by anyone of the conventional methods. After packing, $\mathrm{CO}_{2}$ forced into the mould at a pressure of about $1.4 \mathrm{~kg} / \mathrm{cm}^{2}$. The sodium silicate present in the mould reacts with $\mathrm{CO}_{2}$ and gives a hard substance called the silica gel.

$\mathrm{Na}_{2} \mathrm{SiO}_{2} \cdot \mathrm{xH}_{2} \mathrm{O}+\mathrm{Co}_{2} \longrightarrow \mathrm{Na}_{2} \mathrm{Co}_{3}+\left(\mathrm{SiO}_{2} \cdot \mathrm{xH}_{2} \mathrm{O}\right)$ 
The silica gel is a hard substance like cement and hence helps in binding of sand grains. The method of introducing the gas must be simple, rapid and uniform throughout the sand body. Normally time taken to harden a medium size body is about 20 to 30 seconds. Over-gassing is wasteful and results in deterioration of sand.

\subsection{The following are amount of ingredients in moulding sand mixer:}

Table No 3.1

Additives

\begin{tabular}{|l|l|l|l|l|}
\hline $\begin{array}{l}\text { Sand } \\
\text { type }\end{array}$ & Weight & $\begin{array}{l}\text { Sodium } \\
\text { silicate } \\
\text { liquid }\end{array}$ & $\begin{array}{l}\text { For cores } \\
03 \text { powder }\end{array}$ & $\begin{array}{l}\text { For moulds } \\
\text { Red oxide } \\
\text { powder }\end{array}$ \\
\hline 1. Quartz & $100 \mathrm{kgs}$ & $5.5 \mathrm{kgs}$ & $1 \mathrm{~kg}$ & $200 \mathrm{grams}$ \\
\hline 2.Silica & $250 \mathrm{kgs}$ & $11 \mathrm{kgs}$ & $1 \mathrm{~kg}$ & 200grams \\
\hline
\end{tabular}

\subsection{Advantages over other methods:}

Operations is speedy.

Castings obtained have closed tolerances and good surface finish.

Banking operations for hardening the cores and moulds are avoided.

Accurate castings with sharp corners can be made. The process being simple, requires semi skilled labour.

Less possibility of distortion of mould and core during the process of hardening.

3.5 Final arrangement of cores in shape of Hypoid pinion mould:

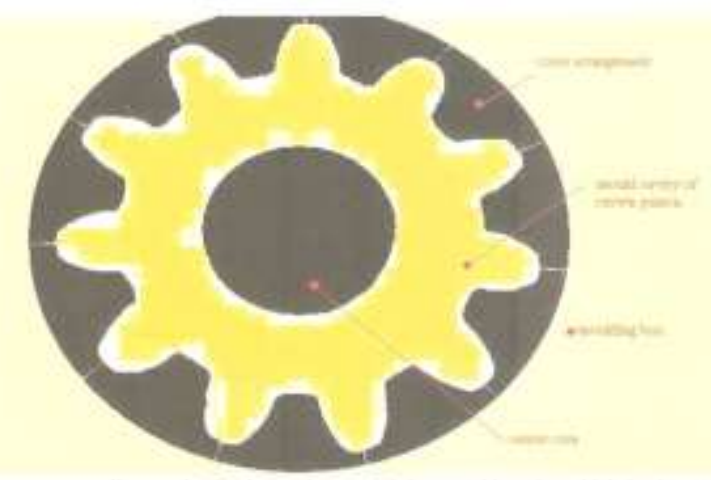

Fig 3.2

Finally we arrange all cores in the form of Hypoid pinion mould cavity which is shown in above fig. 3.2 after arrangement of cores we put a moulding box over this arrangement, then fill the gap between moulding box and cores with sodium silicate sand mixer. After packing, $\mathrm{CO}_{2}$ forced into the mould at a pressure of about $1.4 \mathrm{~kg} / \mathrm{cm}^{2}$. The sodium silicate present in the mould reacts with $\mathrm{CO}_{2}$ and gives a hard substance called the silica gel. Next necessary repairs have done on Hypoid pinion mould cavity.

\subsection{Gating for metal flow into mould cavity:}

The gating system is the network of channels used to deliver the molten metal from outside the mould into the mould cavity. The pouring cup is the portion of the gating system that initially receives the molten metal from the pouring vessel and controls its delivery to the rest of the mould. From the pouring cup, the metal travels down the spruce (The vertical portion of the gating system), then along horizontal channels (called runners), and finally through controlled entrances, or gates, into the mould cavity.

If is poured very slowly in a mould cavity, then solidification may start while it is not even completely filled up. If pour very fast, high velocity will erode mould surface. Thus optimum pouring velocity is essential.

Gates, depending on their potion may be top parting and bottom type. In the case of top gating the molten metal is poured down the head or riser. Thus erosion of mould by dropping metal should be ensured by making hard mould. In this case hot metal remains at top and thus proper temperature gradients are established for directional solidification towards the riser. Top gate may be made to serve as riser.

Top gates are usually limited to small and simple mould or longer castings made in moulds of erosion resistant material. Top gating is not advisable for light and oxidisable metals like aluminium and magnesium because of a fear of entrapment due to turbulent pouring.

In the parting line gating system, the metal enters the mould cavity at same level as the mould joint or parting line. The sprue is connected to the casting through a gate in a horizontal direction. It is thus possible to provide skimbob or skimgate to trap any slag or sand in the metal. The choke serving as a restriction controls the rate of flow.

In the bottom gating system, the molten metal flows down the bottom of the mould cavity in the drag and enters at the bottom of the casting and 
rises gently in the mould and around the cores. Bottom gates are best suited for large sized steel castings. Turbulence and mould erosion are least in the case. However time taken to fill up mould is more.

Directional solidification is difficult to achieve in bottom gating because the metal continues to lose its heat into the mould cavity and when it reaches the riser, metal becomes much cooler.

\subsection{Aspiration effect:}

In a faulty mould design, the metal velocity may be high and thus pressure may fall below atmosphere and the gases originating from baking of organic compounds may alter molten metal stream, producing porous castings.

Two cases are possible in moulds where negative pressure may be experienced. One is in the sprue design and other where sudden change in direction of flow takes place.

\subsection{Gating ratio:}

Gating ratio is defined as the ratio of sprue area to total runner area to total gate area. A gating ratio of 4:3: 2 results in pressurized system. In the system, the proportions of sprue, runner and gate cross-sectional area are so arranged the back pressure is maintained on the gating system by a fluid film restriction at the gates. This system is adopted for metals like steel, iron, brass etc.

The pressurized gating system is kept full of metal. The back pressure due to restriction at the gates tends to minimize danger of the metal pulling away from the mould walls with consequent air aspiration. Pressurized system are generally smaller in volume for a given metal flow rate than unpressurised ones. Thus, less metal is left in the gating system and casting yield is higher. However, severe turbulence may occur at junctions and corners unless careful streamlining is employed. High velocity and turbulence result in entrapment, dross formation and mould erosion.

In case of unpressurised system the primary restriction to the fluid is at or very near to the sprue. The gating ratios likes 1: 3:3,1: 2: 2 will produce an unpressurised system. Such a system is adopted for light, oxidizable metals like aluminium and magnesium where the turbulence is to minimize by slowing down the rate of metal flow.

In the case of pressurized system careful design is required to ensure them being kept filled during pouring. Drag runners and cope gates aid in maintaining a full runner, but careful streamlining is essential to eliminate the separation effects and consequent air aspiration.

\section{PROCEDURE FOR HYPOID PINION}

\subsection{The procedure of calculating the following aspects}

Number of feeders required for refilling of shrinkage cavity.

Size of Exothermic material required for keeping metal in molten state upto completion of solidification.

Dead weight for restricting buy ounce force of molten metal.

Time required for solidification process.

Quantity of molten metal required for Hypoid pinion casting.

\subsection{Calculation:}

We have done this methoding calculation by using modulus method. According this method first we calculate the modulus of casting.

4.2.1. Modulus of casting $=$ volume of casting / surface area of casting

Volume of casting $=($ volume of the pinion between RCD and CHD)+(volume of the pinion-between OD and RCD)

Where $\mathrm{RCD}=$ Root circle diameter

$\mathrm{OD}=$ Outer diameter of Hypoid pinion

$\mathrm{CHD}=$ Center hole diameter

Volume of pinion between RCD and

$\mathrm{CHD}=0.7855 *\left(R C D^{2}-C H D^{2}\right)$

*pinion height $=0.7855 *\left(85.5^{2}-48^{2}\right)$

$* 43.2=1,69,880 \mathrm{~mm}^{3}$

Volume of pinion between OD and RCD = $0.7855 *\left(125^{2}-855^{2}\right) * 42 * 0.45=1,23,440 \mathrm{~mm}^{3}$

Volume of casting $=1,69,880+1,23,440=$ $2,93,320 \mathrm{~mm}^{3}$

Surface area of casting $=($ surface area between $\mathrm{RCD}$ and $\mathrm{CHD}) * 2+($ surface area 
Between $-\mathrm{OD}$ and $\mathrm{RCD}) * 2+$ (surface area of center hole $)+($ surface area of teethes of pinion)

$$
=\left(0.7855^{*}\left(85.5^{2}-48^{2}\right)\right)+\left(0 . 7 8 5 5 ^ { * } \left(125^{2}-\right.\right.
$$

$$
\begin{aligned}
& \left.\left.\left.85.5^{2}\right) * 2\right)+0.7855 * 48 * 43.2\right)+(19.75 * 42 * 2 * 18) \\
& \quad=7,865+5,878+6,514+29,862 \\
& =50,119 \mathrm{~mm}^{2}
\end{aligned}
$$

Modulus of casting $=$ volume of casting / surface area of casting $=2,93,320 / 50,119=5.85$

Note: modulus of riser always $20 \%$ more than casting modulus for metal flow into mould, so

Riser modulus $=1.2 * 5.85=7$

Feeder diameter $=6 *$ square root of $7.38=16.3$ inches

Number of feeders $=106.98 /((2 * 16.3)+7.38)=3$ numbers

Note from table we have taken 3 numbers of 11 inches size exothermic materials.

4.2.2. Quantity of molten metal required for pouring $=$ volume of casting $*$ density of cast steel $=2,93,320 * 7.8 \mathrm{gr} / \mathrm{cm}^{3}$

$$
=2,300 \mathrm{kgs}
$$

4.2.3. Dead weight on mould $=$ (top surface area of pinion * height) / factor of safety $=(((7865+5878) / 2) * 0.45) / 1.4=2300 \mathrm{kgs}$

4.2.4. Pouring temperature $=1590$ degrees

\section{PREPARATION OF MOLTEN METAL FOR POURING}

A good care has to be exercised during melting of metal in order to obtain defect free casting. A variety of furnaces are available to melt the metal. Their selection obtain depends on the kind of metal, quality of metal to be melted, fuel costs and other factors. Heat in the furnace may be produced by combustion of coal, oil or gas, or by electric arc or electric resistance.

\subsection{In this organization induction furnace is used for melting of metal:}

5.1.1 About induction furnace:

The principle of operation of the induction furnace is the phenomena of electro magnetic induction.

The induction (generation) of the electrical current in a conductive metal (charge) placed within a coil of conductor carrying electrical current is known as electromagnetic induction of secondary current.
Induction furnace work in the principle of electromagnetic induction. High frequency electric current passing through a water cooled copper coil induces an electric current in the charge (metal in the furnace to be melted) since there is no way out this current it expands itself in heating the charge which melts eventually.

The alternating current applied to the coil produces a varying magnetic field which is concentrated within the helical coil. This magnetic field passing through the charge induces secondary current in the charge piece. The current circulating in the charge produces electrical losses which heat the charge and eventually melt it. Through a water-cooled coil which acts as the primary coil of a transformer. The charge i.e. steel scrap or other conductive metal, act as the secondary coil of a transformer. A highfrequency current is passed through the primary coil generates a magnetic flux which cuts the secondary coil i.e. the metallic charge and induces an electromotive force, emf in the charge and the charge gets heated up. When the temperature rises above the melting point of the metallic charge, it changes to liquid phase and tapped out of the furnace for further processing.

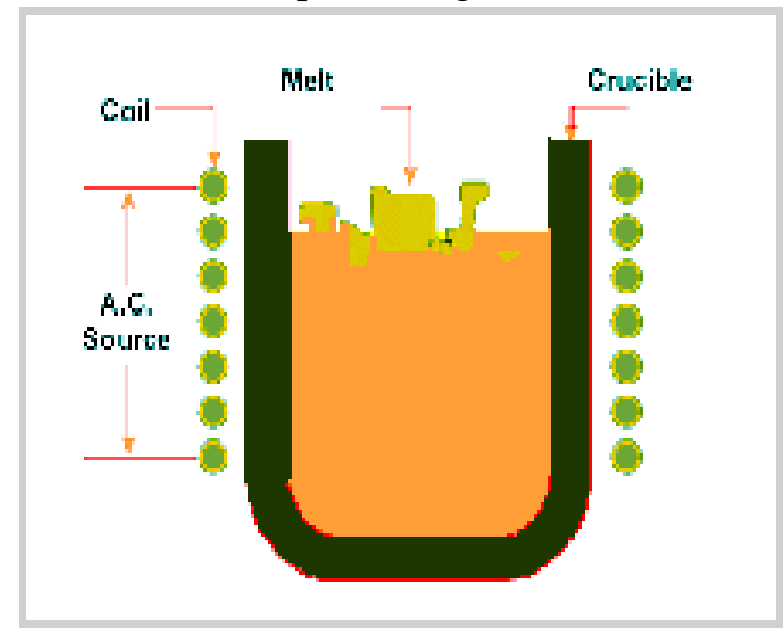

Fig 5.1 shows structure of induction furnace.

\subsection{How induction heating is a better way:}

Induction heating is a subfield of industrially used electric heating. All electrically - conductive materials can be heated quickly and cleanly with pollution free induction heating. Features include: Heating time and temperature can be precisely controlled.

There is no smoke or soot pollution; 
Heating operation can be integrated in semi automatic production sequences;

Induction equipment can usually be operated by unskilled personal.

\subsection{Advantages of induction heating}

Very fast partial hardening;

High production rates;

Significant reduction in pollution, distortion, forging scale, energy and space requirements;

High degree of reproduction and automation;

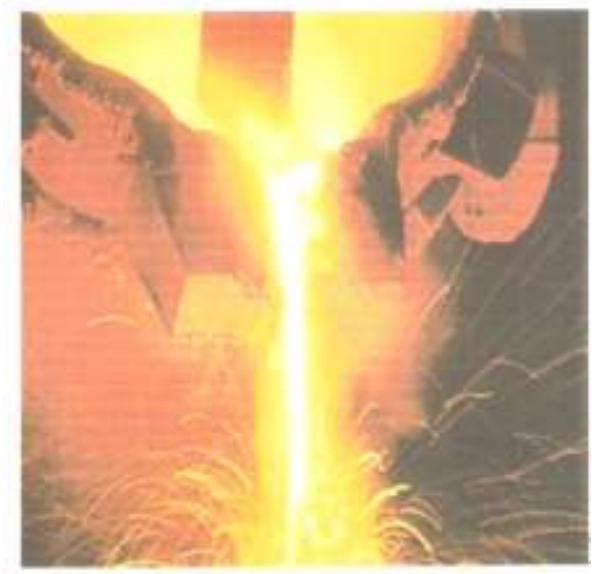

Fig 5.2 describes about molten metal.

\section{Melting procedure:}

Before melting of metal we should prepare induction furnace by arranging refractory sand material on inner surface of the induction furnace for reducing damage of coils.

Next check the arrangement of cooling water circulation through induction coils from over head tank for efficient working furnace.

Fill the furnace with metal billets and metal scrap as per methoding calculation and also add ferrous alloys as per requirement.

In melting process another important thing is removal of slag. The quality of casting is mainly depending on the slag removal. Slag is nothing but the impurities floating over the molten metal, it causes so many problems like casting defects to end casting product.

Melts the metal upto tapping temperature of 1635 degrees of centigrade ( for IS2708 G-111 ). After reaching of tapping temperature taps metal from the furnace without slag.

\subsection{Colour Coding returns:}

Table 5.1

\begin{tabular}{|c|c|c|}
\hline S. No & Specification of material & code \\
\hline 1 & Low carbon steel (0.25\%) & Red oxide \\
\hline 2 & $\begin{array}{c}\text { IS 2707, EN 8, EN 9 (0.35 to 0.45), } \\
\text { HY19563 }\end{array}$ & Pink \\
\hline 3 & IS 2708, IS 2644 (0.25 TO 0.33) & Pink \\
\hline 4 & $\begin{array}{c}\text { IS 2640, IS2708 (High } \\
\text { molybdenum) }\end{array}$ & Blue \\
\hline 5 & $\begin{array}{c}\text { EN 19, IS 4896, IS 5517, GS 42, } \\
\text { Crom04 (Molybdenum 0.2\% to } \\
0.35 \%)\end{array}$ & Yellow \\
\hline 6 & IS 276 : GR-1\&2 (Mn-steel) & Navy blue \\
\hline 7 & IS 276: GR-3 (Mn-steel) & White \& Yellow \\
\hline 8 & IS 276 : GR-4 (Mn-steel) & White \& Yellow \\
\hline 9 & Cast Iron & Appeal green \\
\hline 10 & S.G Iron & Dark green \\
\hline 11 & $\begin{array}{c}\text { IS 4771,HY-19592,19593,19594 } \\
\text { (High chromium) }\end{array}$ & Sky blue \\
\hline 12 & With special alloys like HY 19573 & Yellow \& Slack \\
\hline
\end{tabular}

\subsection{Tapping temperatures of different} material:

Table 5.2

\begin{tabular}{|l|l|l|l|}
\hline $\begin{array}{l}\text { S. } \\
\text { No. }\end{array}$ & $\begin{array}{l}\text { Type of } \\
\text { material }\end{array}$ & $\begin{array}{l}\text { Tapping } \\
\text { temperature }\end{array}$ & Variation \\
\hline 1 & Cast Steel & 1620 & $+/-30$ \\
\hline 2 & Cast Iron & 1300 & $+/-20$ \\
\hline 3 & S.G Iron & 1520 & $+/-20$ \\
\hline 4 & Mn-Steel & 1635 & $+/-20$ \\
\hline
\end{tabular}

Note: Temperature in degrees of centigrade.

\subsection{Spectrometric analysis}

In steel castings the quality casting means not only defect less casting and also consider the compos ion of elements in the casting material used for casting product, because the working capability of any casting component is mainly depends on the properties of that casting material. A little change in composition causes a wide change in properties. According to the application of cast product customer proposes the material grade, hence we have to produce the product with proper composition of elements as per customer order. So we should measure each element concentration in molten metal before pouring into mould cavity. For effective elemental analysis spectrometers are used, these spectrometers are working on the principle of spectrum. The analysis through spectroscopy is called as spectrometric analysis. 
5.7.1 Effects of elements on steel:

Alloying elements are added to effect changes in the properties of steels. Some of the different alloying elements added to the basic system of iron and carbon, and what they do to change the properties or effectiveness of steel.

\subsubsection{Carbon:}

As I've already stated, the presence of carbon in iron is necessary to make steel. Carbon is essential to the formation of cementite (as well as other carbides), and to the formation of pearlite, spheroidite, bainite, and iron-carbon martensite, with martensite being the hardest of the microstructure, and the structure sought after by knifemakers. The hardness of steel (or more accurately, the hardenability) is increased by the addition of more carbon, 0.65 percent. Wear resistance can be increased and increase brittleness. The steels of interest to knifemakers generally contain between 0.5 and 1.5 percent carbon. They are described as follows:

Low Carbon : 0.4 percent

Medium Carbon : 0.4 - 0.6 percent

High Carbon : $0.7-1.5$ percent

Carbon is the single most important alloying elements in steel.

\subsubsection{Manganese}

Manganese slightly increases the strength of ferrite, and also increases the hardness penetration of steel in the quench by decreasing the critical quenching speed. This also makes the steel more stable in the quench. Steels with manganese can be quenched in oil rather than water, and therefore are less susceptible to cracking because of a reduction in the shock of quenching. Manganese is present in most commercially made steels.

\subsubsection{Chromium}

As with manganese, chromium has a tendency has a tendency to increase hardness penetration. This element has many interesting effects an steel. When 5 percent chromium or more is used in conjunction with manganese, the critical quenching speed is reduced to the point that the steel becomes air hardening. Chromium can also increase the toughness of steel is the tendency to as stainless steels. A more accurate term would be stain resistant. Stainless tool steels will in fact darken and rust, just not as readily as the nonstainless varieties. Steels with chromium also have higher critical temperatures in heat treatment.

\subsubsection{Silicon}

Silicon is used as a deoxidizer in the manufacture of steel. It slightly increases the strength of ferrite, and when used in conjunction with other alloys can help increase the toughness and hardness penetration of steel.

\subsubsection{Nickel}

Nickel increases the strength of ferrite, therefore increasing the strength of steel. It is used in low alloy steels to increase toughness and harden ability. Nickel also tends to help reduce distortion and cracking during the quenching phase of heat treatment.

\subsubsection{Molybdenum}

Molybdenum increases the hardness penetration of steel, slows the critical quenching speed, and increases high temperature tensile strength.

\subsubsection{Vanadium}

Vanadium helps control grain growth during heat treatment. By inhibiting grain growth it helps increase the toughness and strength of the steel.

\subsubsection{Tungsten}

Used in small amounts, tungsten combines with the free carbides in steel during heat treatment, to procedure high wear resistance with little or no loss of toughness. High amounts combined with chromium gives steel a property known as red hardness. This means that the steel will not lose its working hardness at high temperatures. An example of this would be tools designed to cut hard materials at high speeds, where the friction between the tool and the material would generate high temperatures.

History of Spectroscope:

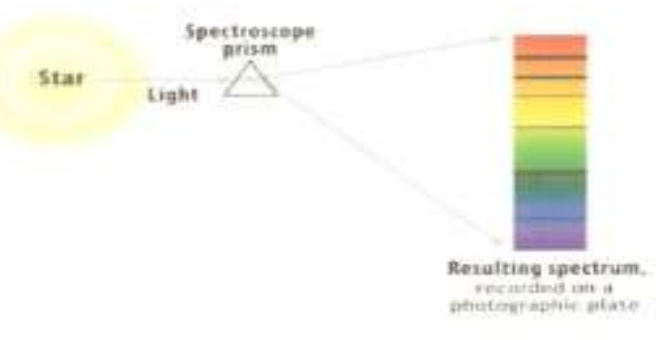

Fig 5.3 
Chromatic decomposition of light had been known for a long time, if only through the rainbow. In the second half of the $17^{\text {th }}$ century, Issac Newton named "spectrum" the colures figure obtained by scattering sunlight through a prism. Beginning in 1666, Newton demonstrated the fixity of the colures thus formed, and synthesized white light by mixing these colures shown in Fig 5.3.In 1814, Joseph von Fraunhofer invented the diffraction grating (transmission). After fitting it onto a theodolite, he resumed wollaston's work and marked the relative positions of several hundreds of black lines. He was, however, unable to provide a satisfactory explanation for their presence.

They explained Fraunhofer's black lines as being caused by the absorption of solar light by metal vapours present in the colder layers surrounding the sun. they even identified the element responsible for some of these black lines. This work paved the way for atomic spectro chemistry and announced the advent of modern physics.

In 1887 Heinrich Hertz proved that visible light is a section of the electromagnetic spectrum. From this result, it follows that light has a frequency ( $\mathrm{s}$ in $1 / \mathrm{s}$ ) and a wavelength ( $\lambda$ in $\mathrm{m}$ or $\mathrm{nm}$ ), respectively, where in both values can be converted into each other with the help of the constant $\mathrm{c}$ (speed of light) $(v=\mathrm{c} / \lambda)$. Spectroscopy almost always works with the wavelength $\lambda$ in units of $\mathrm{nm}(=10-9 \mathrm{~m})$. The symbol for the wavelength is "lambda" $(\lambda)$ and the unit is either nanometer $(\mathrm{nm})$ or micrometer (or micron, $\mu \mathrm{m}$ ). the symbol for frequency is "nu" $(\mu)$ and the unit is either hertz or sec

\subsection{Different types of Spectroscopes:}

5.8.1 Atomic level

\subsubsection{Atomic Absorption spectroscopy (AAS):}

Principle: The sample is vaporized by aspiration of solution into a flame or evaporation from electrically heated surface (temperature range: $1800-31000 k)$. at this condition where the individual atoms co-exist, a beam of light is passed through them. The atoms will absorb in the visible and ultraviolet region resulting in changes in electronic structure (exited state). So, the resultant light beam coming out of the sample will be missing the light in the corresponding wave length, which is a measure of the characteristics of the sample. Instrumentation: sources emitting radiation characteristic of element of interest (hollow - cathode lamp), flame or electrically heated furnace, monochromator, detector (photomultiplier) and recorder.

The following is the simplified outline of the instrumentation:

Applications: This is the most widely used technique for the quantitative determination of metals at trace levels (0.1 to $100 \mathrm{ppm})$, which present in various materials. It utilizes Beer Lambert Law for the analysis and a standard curve is obtained by plotting absorbance vsconcentration of the samples taken.

The usual procedure is to prepare a series of standards and the samples are separately aspirated into the flame, and the absorbances are read from the instrument. The plot will give the useful linear range and the concentrations of the samples can be found out from the plot.

Disadvantages: Sample must be in solution or at least volatile. Individual source lamp and filters needed for each element, since, each metal has its own characteristic absorption

\subsubsection{Atomic Emission Spectroscopy (AES)}

Principle: this is simply called as 'Flame Photometry', and measures the atoms excited by a flame (temperature range: 2000 - 31000k) and not by light source as in the atomic absorption case. After excitation, atoms will readily lose the gained energy and revert back to the ground state and the emission occurs. It is that emission that actually being measured. The wavelengths of the emitted light will almost be similar as those that were absorbed in the atomic absorption, since exactly the same energy transitions occur, except in the order.

Instrumentation: A simple flame photometer consists of burner, nebulizer, monochromator, detector and recorder. The following is the simplified figure:

Applications: It is used exclusively in the quantitative determination of metals in solution, 
especially alkali and alkaline earth in the given samples. The principle is like that described for atomic absorption. Qualitative determination is also possible as each element emits its own characteristics line spectrum.

Disadvantages: intensity of emission is very sensitive to changes in flame temperature. Usually, spectral interference and self-absorption are also encountered which affects the precision of the measurement. Further, a linear plot of absorbance against concentration is not always obtained.

5.8.1.3 Plasma emission spectroscopy:

Principle: Mostly referred as inductively coupled plasma (ICP) Emission Spectroscopy, is also an atomic emission technique, most closely related to the preceded flame photometry expect that the atoms and ions present in the sample are excited in high temperature gas plasma. Since the plasma provides very high temperature and hence the energy, almost all the atoms present in the sample can be excited with this technique ending up with high efficiency (a hotter source increases both atomization efficiency and excitation efficiency). Thus, the emissions from the atoms would be more intense and even very small concentrations of metals/metal ions can be detected and accurately measured.

Instrumentation: this is basically an emission spectrometer comprising nebulizer, RF coil, ICP Source (Argon plasma), monochromator, detector and recorder.

A plasma source or jet is a flame-like system of ionized, very hot flowing argon gas. At high temperatures ( $(6000 \mathrm{k})$ a gas such as argon will contain a high proportion of ions and free electrons constituting plasma (This ionization is initiated by "Tesla" coil). Additional energy may be supplied to the electrons in the plasma by the application of an external electromagnetic field through RF coil. By collisions between the electrons and the other species in the plasma this additional energy is uniformly distributed. As the collisions increase, the energy transfer becomes more efficient, which leads to a substantial temperature enhancement to a range of $8000-$
$10000 \mathrm{k}$. It is the temperature at which leads to a substantial temperature at which the samples are introduced and analysed.

Applications: Similar to atomic emission spectroscopy but it covers very widespread for both qualitative and quantitative analysis of metals and some non-metals too, at trace levels. Because of the high temperature and homogeneity of the source, it offers better signal stability and hence the analytical precision.

The technique when utilizing an optional emission detector is termed as Inductively coupled PlasmaOptical Emission Spectrometer (ICP - OES) and if it is utilises a mass spectrometer ( refer section 9.6) as detector then it is termed as Inductively Coupled Plasma - Mass Spectrometer ( ICP MS).

Disadvantages: Samples require dissolution before analysis. Instrumentation is complex and requires high operator's skill and is very expensive.

\section{Fluorometry: Atomic Fluorescence}

This technique is not widely used though its counterpart - the molecular fluorescence is applied well to the analytical studies. The principle of atomic fluorescence is that when atoms are elevated to higher energy levels, they sometimes return to the ground state through a pathway, which has several intermediate electronic states, before reaching to the actual ground state. Such series of fall through the electronic levels accompany by light emission which is atomic fluorescence. The intensity of this emitted light is measured at right angles to the incident light and related to concentration. User are similar to AAS and AES.

5.8.2 Computer controlled vacuum spark emission spectrometer:

In our project the spectrometric analysis has done by using new modern computer controlled vacuum spark emission spectrometer. The analyzer system consists of a direct reading vacuum spectrometer, a digital computer and a data transmission system. The computer system is responsible for the control of the spectrometer as well as for the transformation of measured values 
into element concentration values and their transmission into the plant internal teleprompter network. A great disadvantage of spectrometers is the fact that matrix effects occurs. To solve the problems arising from that - especially in the case of analyses of extended alloying program - either numerous special calibration curve and eliminate the matrix effects by calculation of the line coincidences and the third element influences. The combination of a spectrometer and a digital computer permits rapid determination of the chemical composition of samples by following the second procedure and makes the automatic transmission and documentation of data possible.

5.8.2.1 Features of computer analyzed system:

Qualitative Database Calibration allows
wavelength selection and fast calibration, eliminating time-consuming comparative examination.

Method Development Assistant automatically creates measurement wavelength and calibration curve information as well as correction information if interference is unavoidable.

Automatic wavelength Selection System ensures accurate results with negligible spatial interference. Multiple wavelengths can be selected and tested with no respective interference from multiple samples.

Interference Database stores all interfering elements and the corresponding wavelengths, resulting in an accurate and automatically selected optimal wavelength, while eliminating interfaces and the need to re-measure.

"Analysts want instruments that are precise, reliable, and easy to use," notes Rotbert H.Cliffrord the multi-functional attributes of the software's Assistant functions, simple and accurate measurement is possible - even with hard-to-measure high-matrix samples.

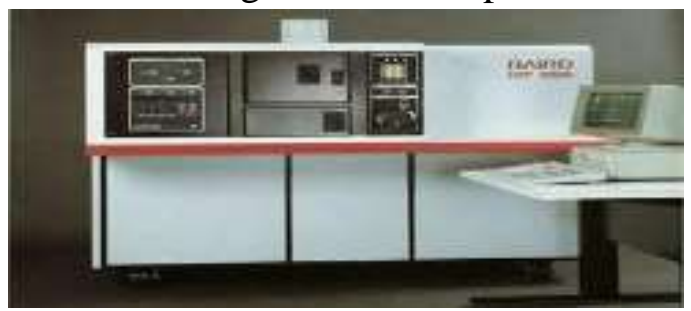

Fig 5.4 Computer controlled vacuum emission spectrometer

\subsection{Requirements for spectrometric analysis:}

An excitation generator (source) that provides the required excitation energy in an amount that is sufficient for ionization

Optics that filter out the desired wavelengths

A detector system that can measure the intensity of light radiation

A display and control system in order to acquire the measured values of the detectors and to control the functions of the spectrometer

A computer with software for easy calculation and illustration of the obtained measured values in percentages for the individual elements.

A calibration

A spark stand or testing probe in order to position the material for the analysis.

\subsection{The Excitation (Source):}

There are different options for ionizing atoms. Common processes are chemical flames (AAS atomic absorption spectroscopy), electrical plasma (ICP - inductive coupled plasma), electrical discharges in vacuum (GDA -glow discharge analyzer), in air (arc excitation), in argon (spark excitation). Here we used last one i.e. argon (spark excitation). Because spark excitation in argon is the main form of excitation in the field of metal analysis and have achieved such a high technical standard that the instruments can also be used outside of the laboratory. Argon as the discharge atmosphere has two important functions, one, it prevents oxidation processes of the highly reactive elements in the plasma, and two, it has relatively heavy and thus immovable atoms, which promote a quick charge balance between electrode and sample. With the effect that practically the entire discharge energy is converted at the sample. The electrode remains cool and is not ablated. To this reason, tungsten can also be used as the electrode and sample. With the effect that practically the entire discharge energy is converted at the sample. The electrode material, even though the element $\mathrm{W}$ can be found up to trace amounts in the metal.

\subsection{The optical system}

The optics is the heart of the spectrometer and definitively determines the performance. For modern optics, the so-called Paschen-Raunge 
mouting has especially proven itself, because it allows the construction of robust system of great light transmitting capacity

\subsubsection{The Paschen-Raunge mouting}

In order to build the optic as compactly as possible, one only used the spectral range between the entrance slit and the grating normal, thus forming the Paschen-Raunge mouting.

The light of the sample is incident at an angle through the entrance slit on the grating and is there reflecting with the wavelength-dependent angle. Because the entrance and exit slits are mounted at the focal plane (Rowland circle), a spectral line emerging into the entrance slit is sharply imaged at a diffraction angle onto the exit slit.

The geometric relationships are actually very simple and allow the calculation of the slit However, despite the highest mechanical precision, an alignment of the slits is required in order to actually filter out the desired wavelengths.

This task requires much experience and care, particularly when one considers that there are up to 50 slits per optic. Changes in the grating position lead to large deviations in the wavelengths and the focusing, then, behind the exit slits, there are detectors, which measure the light intensity of the relevant.

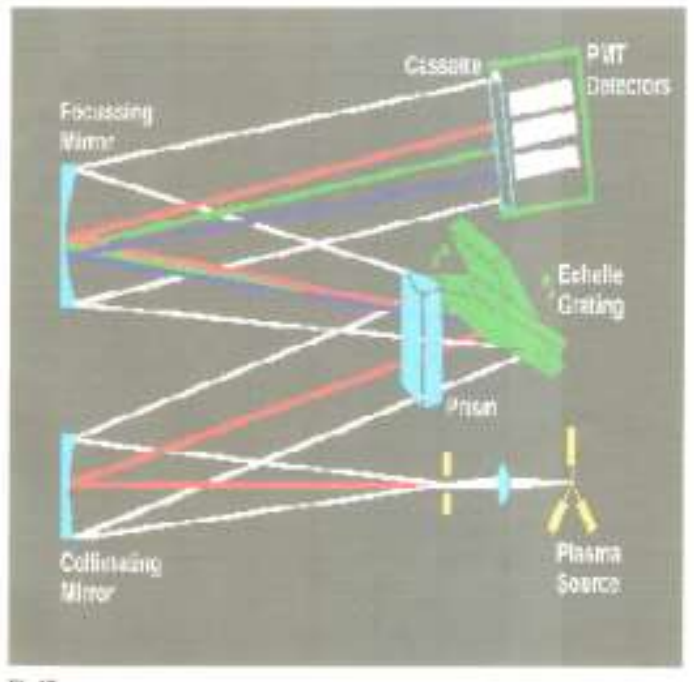

Fig 5.5 shows the working of optics and detectors

\subsection{Detectors for light intensity measurement}

5.12.1 Photo Multiplier Tubes (PMT)

Photomultiplier tubes are vacuum tubes, which accelerate and cumulatively amplify the electrons freed at the photocathode by the light particles (photons)

\section{Principle of the photomultiplier tube (PMT)}

In a high-voltage field. The resulting current is measured and is proportional to the amount of photons (lightly intensity) that appear over large ranges.

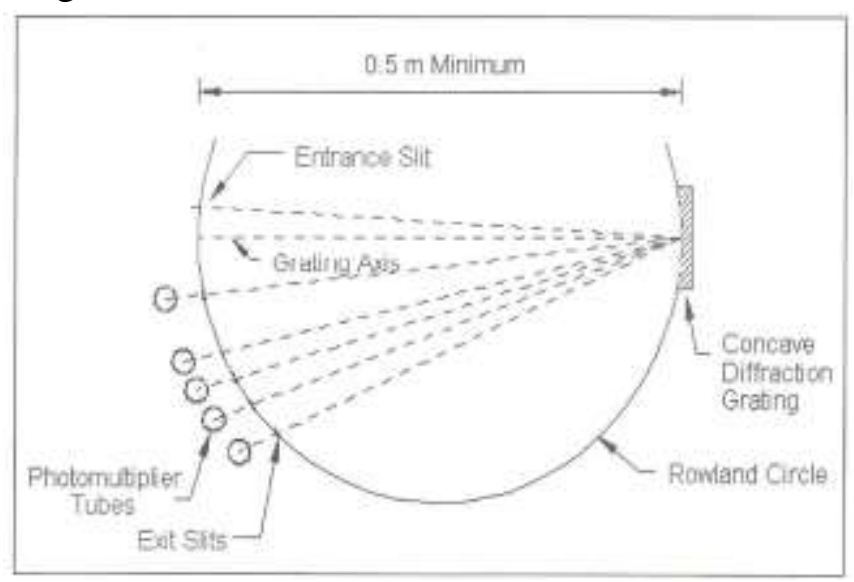

Fig 5.6 Shows working of PMT

5.12.1.1 The special advantages of PMTs are:

Excellent sensitivity also in UV range

Large amplification and dynamic range

Temperature stability

High sensitivity enables the construction of topics with large focal length

(> $500 \mathrm{~mm}$ ) and measurements in the 2nd order

5.12.1.2 Disadvantages are: their higher price, the relatively large construction, and the complicated high-voltage power supply.

\subsubsection{CCD Detectors}

In the last 5 years, so called CCD detectors have come onto the market, whose properties approach those of photomultiplier tubes. CCD stands for charge Coupled Device, thus the detector produces no currents, but instead electrical charges. It operates without a high-voltage power supply and is produced in large numbers as line detectors (the light-sensitive pixels are arranged next to each other) or as an array (the pixels are arranged as a two-dimensional plane). Due to their minimal sizes and the weight can be dramatically reduced. CCD Detectors principle is shown Fig 5.7 


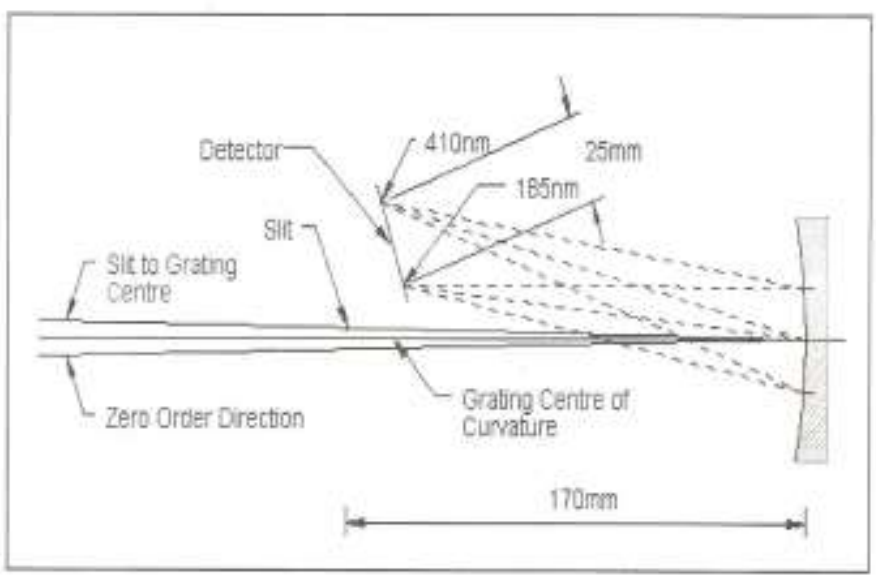

5.12.2.1 Advantages of CCD detectors:

Relatively low price

Small size

Simple power supply

Simple read-out system

Robust

Analytical flexibility, because the entire wavelength range can be covered

\subsection{Evaluation and control}

In general, today the measurement and amplification of signals of the detectors is no longer a problem due to modern microelectronics. In addition, it continues to be perfected more and more. The entire measurement procedure is regulated and controlled by the electronics, so that error operations that could lead to damage can be ruled out.

For instruments with photomultipliers, the tiny electrical currents are charged on capacitors and then the charge of the corresponding capacitors is determined. Here, each detector requires its own output unit (channel). By means of fast analogdigital converts, the signals are digitalized and are then made available to the evaluation computer. The CCD detectors often have integrated evaluation electronics and are simple to evaluate. Thus, the expense relative to measurement is considerably lower and less susceptible to interference.

\subsection{Computer and Software}

Without a meaningful evaluation, our spectrometer can only measure amounts of light defined wavelengths. How does a light-quality measurement instrument become an analysis system?
The instrument must be calibrated, i.e., the amounts of light of known samples are stored. This is done in the form of so-called regression curves. These curves give information on what amount of light corresponds to what concentration of an element. Through the installation of more powerful computer systems and corresponding software packages, today not only is the calibration data stored and analyses displayed, but many other important functions, such as direct material identification, rapid sorting, archiving of measurement, statistical evaluations, data transmission to external computers or networks, etc., are standard features.

\subsection{Calibration}

As already mentioned before, only the calibration turns a spectrometer into an analysis instrument. The generation of a good calibration is a complicated step, which requires much experience and many samples of known compositions. Unfortunately, each spectrometer is unique, so that the calibrations cannot be transferred from one instrument to another without additional work, and cannot be transferred at all for instruments of different construction (PMT detectors, CCD detectors).

The basic principle of a calibration is simple: a known sample is measured, the light amounts of the different elements are marked, and then more samples are measured, whose contents are altered in a manner that is as significant as possible, so that the entire measurement range is uniformly covered. If an unknown sample is measured, one can determine the contents in the unknown sample from the light intensities through comparison with the stored data. The light intensities (digits or counts) are illustrated on the $\mathrm{X}$ axis, and the concentrations in mass\% are illustrated on the $\mathrm{Y}$ axis.

5.15.1 However the following should be consider: The resulting regression curves are matrix dependent, i.e., they are valid only for a certain base metal. A base metal is the element that is present in clear excess (e.g., Fe in steel). Thus, it is not possible, e.g., to simply use the $\mathrm{Si}$ curve from the steel base for A1 materials. For an 
aluminum base, another calibration with other regression curves is required.

5.15.2 There are two essential interference influences that must be considered for calibration: Additive interference. This result from the overlapping of spectral lines, which cannot be clearly separated by the optics. In practice, this means that an element (interferer) leads to the belief of an increased percentage of another element. These interferences can be relatively easily eliminated, because there is a simple additive relation between interfering and interfered element. An additive interference value is, as a rule, negative, i.e., something is taken away from the displayed concentration of the interfered element.

Multiplicative interference. Causes are alloy effects of the sample, whereby the spectral efficiency is influenced by an interference element (e.g., one element is ionized less or vaporized by the presence of another element). This interference is hard to control and the correction values can only be determined empirically. A multiplicative term (positive or negative) leads to an improvement of the regression, thus the name "multiplicative interference". In order to effectively combat these interferences, a calibration should be done with samples from the same alloy groups, e.g., to calibrate the elements $\mathrm{C}, \mathrm{Mn}, \mathrm{Si}, \mathrm{Cr}$, etc. in $\mathrm{CrNi}$ steel by also using CrNi samples and not to accept data from the LAS program. Interference calculations are only practical for a sufficient number (> 10-20) of samples, so that dependencies that are observed are not only coincidental.

\section{Quality of the used calibration samples.}

The debate over which analysis is more correct will never be completely decided (because we would have to be able to count the atoms). From statistics, one can drive that the true value can only be approximated with a certain (high) probability within an interval of error. The samples that are recognized as the best are socalled CRM samples (CRM - Certified Reference Material), which are available from large metal plants or specialized companies. This material has been extensively tested in inter-laboratory tests and forms the recognized standard. Unfortunately, such samples are very expensive and also not available for all alloy and alloy elements. Here, one must make do with samples that have been tested by the manufacturer or in external laboratories. They are not really worse than CRM material and usually have the composition of a real alloy (important for the monitoring of alloy influences), however, the number of independent analyses is usually low and one must precisely estimate the level of confidence in such a sample. Finally, one can only advise the user of a spectrometer to not (only) look at the accuracy of the analysis, but above all at the reproducibility of the measurements and their stability. Small deviations from "correct" desired values are dependent on calibration and do not say anything about the quality of the instrument.

\subsection{Spark stand and sparking probe}

Spark stands and sparking probes each characterize a certain class of spectrometer systems. Instruments with spark stands are called stationary metal analyzers ("laboratory spectrometer"), and instruments with a sparking probe are called mobile/portable metal analyzers ("on-site spectrometers").

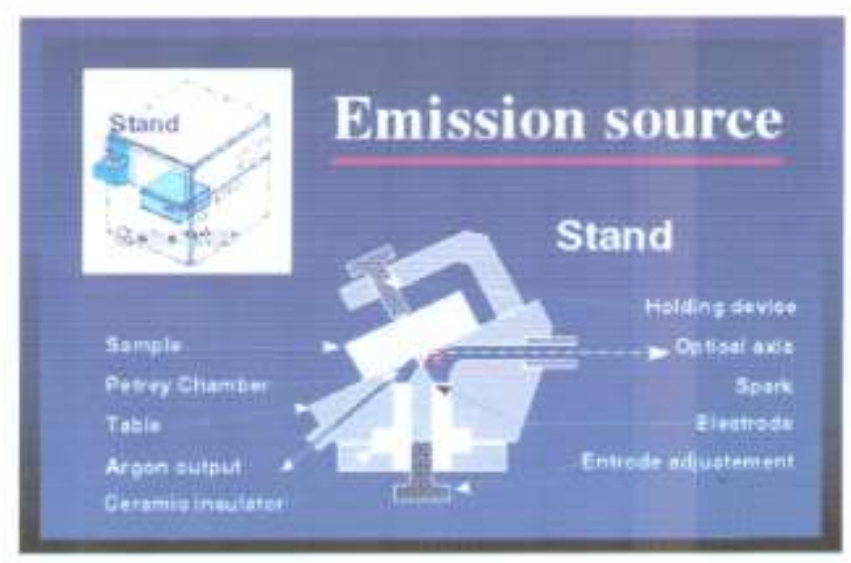

Fig 5.8 Describes setting of probe

\subsection{Sampling}

The stationary spectrometers with spark stands can measure samples of certain geometrics and sizes. If the material does not correspond to the initial conditions, then in the scope of the sample preparation, the material must be processed to the instrument requirements, and often it must also be moulded into a suitable shape. On the other hand, 
through the intensive preparation of the sample and the direct coupling of the spark stand to the spectrometer optics, a highly precise analysis of all alloy elements from trace elements to high contents is possible. Therefore, the stationary metal analysis instrument is predestined for use in the laboratory.

Even the elements $\mathrm{C}, \mathrm{P}$, and $\mathrm{S}$ can be measured simply and very precisely. Thus the identification of 1.4401 and 1.4404 (C content $0.06 \%$ and $0.02 \%$, respectively) is possible.

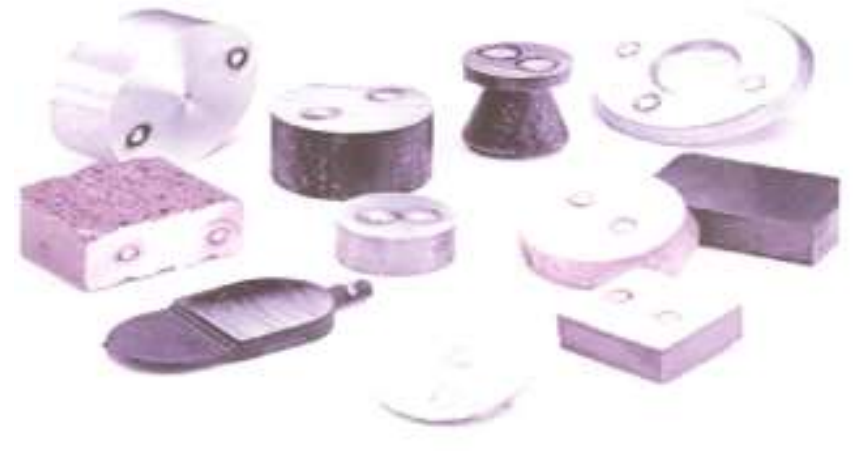

Fig 5.9 Different samples

5.18. Spectrometric analysis on Hypoid pinion material samples while melting:

Customer specified material for Hypoid pinion manufacturing is IS2708, group-3 (1993) which is known as $1.5 \%$ manganese steel in general. We have to produce Hypoid pinion casting with this material composition.

\subsubsection{Procedure:}

First we collect the sample from the furnace in a specified shape.

Prepares the surface of sample by polishing in order to get accurate analysis.

After preparation of sample we put the sample under the electrode probe. Next start the burning process on a spot of sample by adjusting argon gas where atoms of material are getting exited state from ground state.

The atoms are not stable at exited state, they are immediately comes to ground state by emitting light energy in the form of radiation with in fraction of seconds. The wave lengths of emitting light energy is filtering by optics arrangement and measuring by detector.

Wave length of emitting energy is different for different elements as regards their properties.

Lastly the sample data is stored and compared to already stored CRM (certified reference material) sample data, it has done by computer and finally result is displayed on monitor. As per results we charged proper alloys for getting specified composition.

When melting of metal we have taken number of samples at different stages and we have done the above analysis, after that as per result charge the furnace with required ferrous alloys.

\section{PRECAUTIONS TO BE TAKEN WHILE POURING OF METAL INTO CAVITY AND SOLIDIFICATION PROCESS}

Care should be taken to preventing the slag entering while pouring of metal into cavity.

Handle the laddle with care when pouring.

Pouring the molten metal into cavity with optimum velocity because. if is poured very slowly in a mould cavity, then solidification may start while it is not even completely filled up. If pour very fast, high velocity will erode mould surface. Thus optimum pouring velocity is essential.

Pours metal into cavity without shortage which causes damage to casting product.

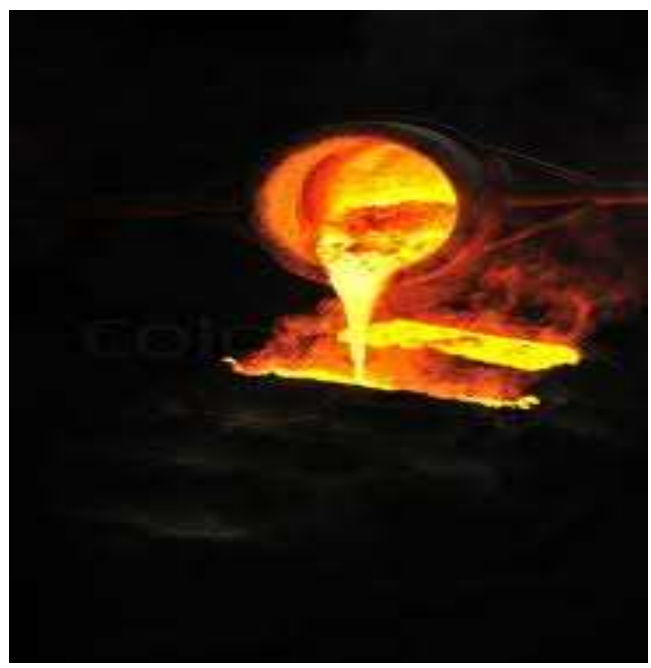

Fig 6.1 Solidification of Metals 


\subsection{Solidification of Metals}

After molten metal is poured into a mould, a series of events take place during solidification of the casting and its cooling to ambient temperature. These events greatly influences the size, shape, and uniformity of the grains formed throughout the casting, which in turn influence its overall properties. The significant factors affecting these events are the type of metal, thermal properties of both the metal and the mould, the geometric relationship between volume and surface area of the casting, and the shape of the mould. As an example considers a pure metal which has a clearly defined melting or freezing point, it solidifies at a constant temperature.

When the temperature of the molten metal is reduced to its freezing point, its temperature remains constant while the latent heat of fusion is given off. The solidification front (solid-liquid interface) moves through the molten metal, solidifying from the mould walls in toward the centre. Once solidification has taken place at any point, cooling resumes. The solidified metal, which we now call the casting, is then taken out of the mould and begins to cool to ambient temperature.

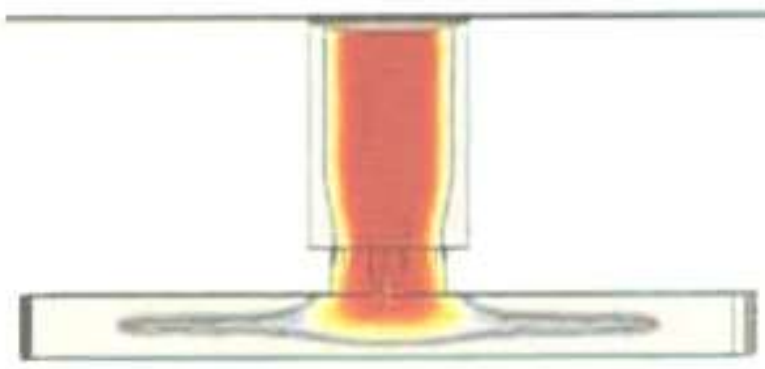

\section{Fig 6.2}

Progressive solidification taking place between Riser temperature gradient and pinion end zones. This will result in certerline shrinkage. Here in case of Hypoid pinion cracking is occurred due to abnormal solidification. Hence we placed some metal chillers at the bottom of the Hypoid pinion mould cavity for achieving directional solidification. The below Fig shows the change of metal structure due to the chilling effect.
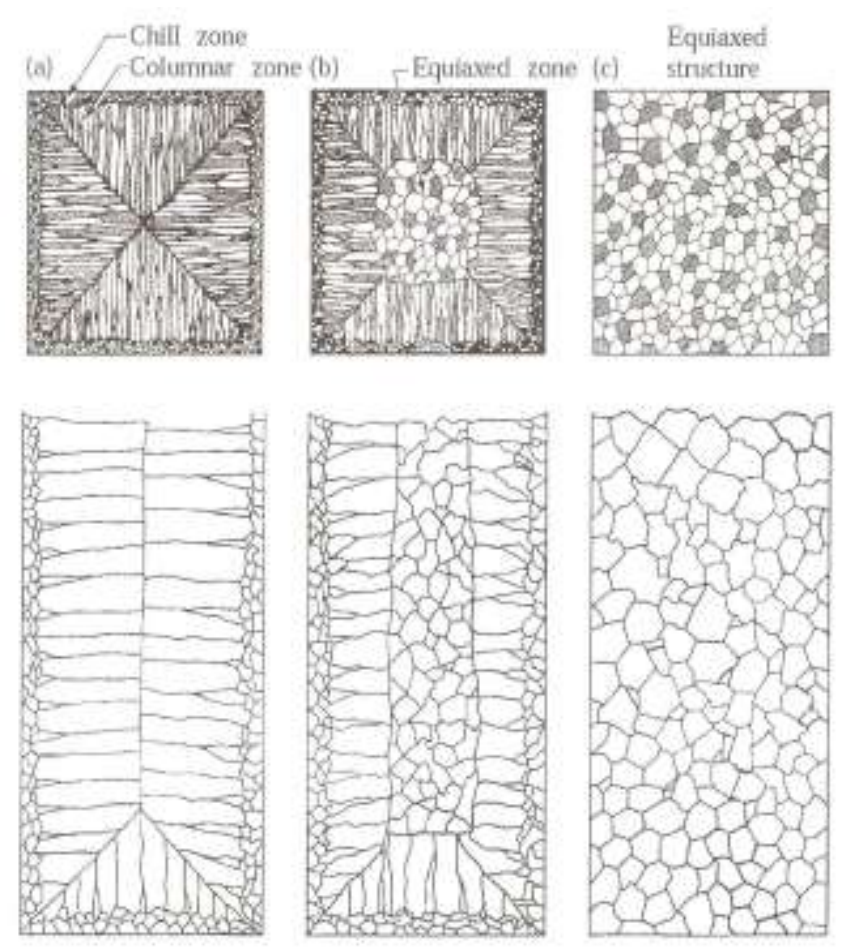

The grain structure of a pure metal cast in a square mould in shown in fig 6.2. At the mould walls, the metal cols rapidly since the walls are at ambient temperature. Rapid cooling produces a solidified skin, or shell, of fine equiaxed grains. The grains grow in the direction opposite to the heat transfer out through the mould. Those grains that have favorable orientation will grow preferentially and are called columnar grains. As the driving force of the heat transfer is reduced away from the mould walls, the grains become equiaxed and coarse. Those grains that have substantially different orientations are blocked from further growth. Such grain development is known as homogeneous nucleation, meaning that the grains (crystals) grow upon themselves, starting at the mould wall.

\section{FETTLING AND CLEANING OF CASTINGS}

Casting require cleaning and trimming before passing them on for machining, or other operations. Fettling is not a precision operation like machining. It's purpose is to remove all unnecessary metal, and the production of a reasonably smooth finish.

For light castings the fettling is limited to removing runners and risers and cleaning off any adhering sand. In heavier and more intricate 
castings, more work is necessary to remove cores, flash metal at joints and surface imperfections.

Generally, higher the metal melting point, the greater the surface roughness of the castings. Thus the heavier castings in grey and malleable cast iron and cast steel call for the most work in fettling.

\subsection{Removal of sand:}

After fettling, any sand adhering to the mould and cores is removed. Method of sand removal is dependent on the size of the casting and the intricacy of the casting.

A simple casting can be easily cleaned by rapping with a hammer followed by wire brushing or shot blasting. If design is more intricate, it takes longer to remove cores and wire reinforcements. Although a wide range of castings are made in green sand moulds, cores are more usually dried. Dried sand, if artificially bonded, does not break easily. On the other hand in such cases casting surface requires little cleaning once the sand is removed. Cleaning by picks are, therefore, used to some extent. But these are heavy and considerable dust is created by their exhaust.

Water sprays in conjunction with pneumatic pick eliminate the dust problem.

Modern automatic units for smaller castings rotate or tumble the castings under the grit blast. Where abrasive is mechanically blasted into castings which are being tumbled on an apron conveyor. Sand or shots could be hurled on the surface of casting by air, water or mechanically by rapidly rotating paddles.

\subsection{Wet process of cleaning (water blast cleaning):}

This process eliminates the dust problem. In the simplest process, agun, easily handled by one man, is used which projects a fine stream of water and sand against the casting at a high pressure.

For heavier equipment the gun operated mechanically from outside the chamber is used. The gun is mounted in a carriage which can be moved the entire length of the room vertically as may be required. The gun swivels in the carriage in a cone of more than $90^{\circ}$. All the motions are controlled by two levers outside the room actuated hydraulically and electrically. This process clean the surfaces of the casting rapidly and thoroughly.

\subsection{Sand Blasting and shot Blasting:}

It consists of projecting, as high velocity, a stream of fine abrasive against the casting to produce a through cleaning of the surface.

In the sand blasting the abrasive used is sand of fairly large grain size. In sand blasting, the sand being in granular form, is comparatively soft and it rapidly breaks into smaller size on impact with a hard metallic surface. Thus the life of the abrasive is less. Further the silica dust can lead to tubercular disease.

In shot blasting, round, or angular, chilled iron shots are used in place of sand resulting in better cleaning and longer life. The selection of round or angular shot depends on the finish desired and the material to be treated. The round shot is generally restricted to the shot blasting of non ferrous castings. Chopped steel wire and steel grit are claimed to be economical because of their long life. The abrasives may be propelled either by pneumatic means or airless.

\subsection{Pneumatic type Shot Blasting Machine:}

A stream of shot falls into a chamber through which compressed air at pressure of 1.5 to $2 \mathrm{~kg} /$ $\mathrm{cm}^{2}$ for grey iron and non-ferrous castings, and upto $6 \mathrm{~kg} / \mathrm{cm}^{2}$ for cast steel is passed. The shot and dislodged material then fall on perforated floor of the cleaning machine. Sand and shots are then separated by a screen and suction dust extraction system.

After removal of adhering sand or refractory, gates and risers are removed by chipping, flogging, shearing, sawing, abrasive wheel cutting and flame cutting.

After removing gates and risers, castings are given one or more finishing operations like polishing, brushing and buffing. The purpose is to smooth the gate and riser areas of the casting, remove any excess metal remaining on the casting and improve appearance.

\subsection{Fettling of Hypoid pinion:}

Fettling of Hypoid pinion is a little complicated, because it is a cast steel product which has high melting temperatures. So we used the following 
pneumatic tools for Hypoid pinion fettling process.

They are as follows

Pneumatic, Vibrating Chippers

Pneumatic Hand grinders

And also used oxy-acetylene gas flames.

7.5.1 Pneumatic chipper MR-22

Pneumatic chipper are intended for fettling of castings, chipping out voids in forging, pipe clamping, conditioning of seams and other works.

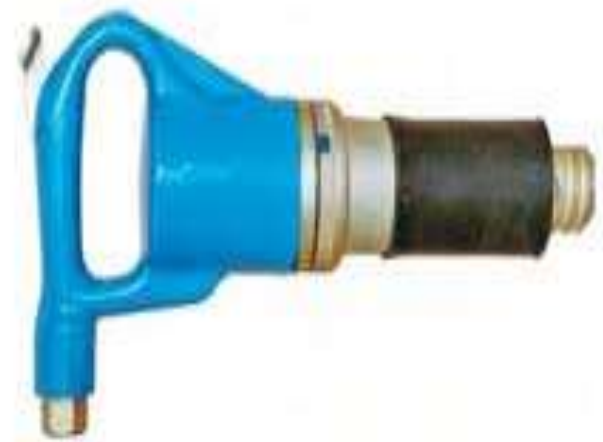

Fig 7.1 Pneumatic chipper

Currently JSC 'Tomsk Vakhrushev electromechanical plant' produces two types of hand-operated chippers; they are MR-22 and MR36.

These chippers are generally applied in metallurgy and have been estimated at their true worth by many specialists. However the field of chipper's application is getting larger.

MR-22 chippers are used for fettling of mediumsize castings, conditioning of seams and defects of rolled stock. MR-36 chippers are used for fettling of large-size castings, chipping out defects on feed and rolled stock.

The MR-22 and MR-36 chippers differ in length of barrel, striker, housing and sheathing. Chippers are delivered with hexagon chipping bush for setting the chisel.

Chipper represents an air percussive pneumatic machine with drill valve chest working under the action of compressed air.

Chipper is comprised of an air distribution percussion mechanism, a handle unit with a builtin starting device.

7.5.1.1 Advantages:

Starting device mantled on the air distributing and air percussion pneumatic mechanisms and liked to the chipper's body comprise a vibroprotective spring system.

Compared eith the analogs, decreased weight of the hammer lightens its operation.

\subsubsection{Specifications:}

Compressed air pressure, MPa 0.49

Impact energy, J, min 22

Impact frequency, s-1, $\min \quad 25$

Specific air consumption, $\mathrm{m} \quad 3 / \mathrm{min}-\mathrm{Kw}, \max 2$

Weight, kg, max 7.2

7.5.1.3 Testing

Inspection Methods

Destructive:

Sectioning, Machining, Mechanical testing

Chemical testing

Non-Destructive:

Visual : large external defects

Dimensional : size defects

Radiography : internal holes

Ultrasound : internal discontinuities

Eddy current : hardness, structure

Magnetic particle: sub-surface discontinuities

Dye Penetrant : defects with opening to surface.

\subsection{Magnetic particle inspection}

Magnetic particle inspection is a method for detecting cracks, laps, seams, voids, pits, subsurface holes, and other surface, or slightly subsurface, discontinuities in ferromagnetic materials. Magnetic particle inspection can be only on ferromagnetic materials (iron and steel). It can be performed on raw material, billets, finished and semi-finished materials, welds, and in-service assembled or disassembled parts. Magnetic particles are applied over a surface either dry, as a powder, or wet, as particles in a liquid carrier such as oil or water.

\subsection{Principle of magnetic particle Inspection}

Magnetic particles inspection uses the tendency of magnetic lines of force, or flux, of an applied field to pass through the metal rather than through the air. A defect at or near the metal's surface distorts the distribution of the magnetic flux and some of the flux is forced to pass out through the surface. The field strength is increased in the area of the defect and opposite magnetic poles form on their side of the defect. Fine magnetic particles applied 
to the part are attracted to these regions and form a pattern around the defect. The pattern of pattern of particles provides a visual indication of a defect.

\subsubsection{Methods of Examination:}

Magnetic particle examination generally consists of the application of magnetic particles; magnetization; determination of field strength; special examination techniques; and demagnetization and post examination cleaning. Each of these steps will be described in the following paragraphs.

7.7.2 Application of magnetic particles:

The magnetic particles used can be nonfluorescent or fluorescent (dependent on the examination required) and are applied suspended in a suitable substance. Fluorescent particles are preferred due to their higher sensitivity.

a. Wet continuous Method. Unless otherwise specified, use only the wet continuous method. In the wet continuous method, the particle suspension is liberally applied to wet all surfaces of the part. The magnetizing current is applied at the instant the suspension is diverted from the part. Apply three shots of magnetizing current, each $1 / 2$ second long.

Wet suspensions of fluorescent particles, either I water or oil, should be used for most overhaul and in-service examinations except where the material, size, or shape of the part prohibits its use.

Water, with a suitable rust inhibitor and wetting agent, may be used as aliquid vehicle, provided that magnetic examination equipment is designed for use or is satisfactorily converted for use with water

b. Dry Continuous Method. This method is not recommended for use on aerospace components because of its lower sensitivity level.

c. Residual Magnetization Method. In this method, the part is magnetized and the magnetizing current is then cut off. If the amperage has been correctly calculated and quality indicator has verified the technique, then one shot will correctly magnetize the part. The magnetic particles are applied to the part after the magnetization. This method is dependent upon the retentiveness of the part, the strength of the applied field, the direction of magnetization, and the shape of the part.

\subsection{Magnetization:}

A Circular. Circular magnetization is induced in the part by the central-conductor method or the direct-contact method.

(1) Indirect induction (central conductor method). Pass the current through a central conductor that passes through the part. When several small parts are examined at one time, provide sufficient space between each piece to permit satisfactory coverage (with particles), magnetization, and examination.

(2) Direct induction (contact method): Pass current through the part mounted horizontally between contact plates. As an example, circular magnetization of a round steel bar would be produced by placing the ends of the steel bar between the heads of the magnetic inspection machine and passing a current through the bars. Magnetic particles applied either during or after passage of the current, or after passage of the current in magnetically-retentive steels, would disclose discontinuities parallel to the axis of the bar.

Critical Examination for Sharp Radii of Hypoid pinion

A critical examination is required for cracks in sharp radii; such as thread parts, splines, gear teeth roots, and abrupt changes in sections, that cause obscuring and non-relevant indications during normal examination practices. The procedure provided herein is the most sensitive method for detecting the early beginnings of inservice fatigue cracks in the sharp, internal radii of ferromagnetic parts. Magnetic particle examination equipment may be used; however, alternating fields are not reliable to provide the necessary high level of residual magnetism. Optical aids are necessary to realize the maximum sensitivity provided by this magnetic particle procedure. Low power $(10 \mathrm{x}-30 \mathrm{x})$ binocular microscopes are recommended. As a minimum, pocket magnifiers of 7 to 10 power may be used 
with the following procedure. Thoroughly clean the part at the sharp radii and fillets where soils, greases, and other contaminants tend to accumulate and at other places where they might be overlooked during a casual or hasty examination.

\subsection{Ultrasonic Testing (UTI)}

Ultrasonic non-destructive testing, which utilizes sound waves at frequencies beyond human hearing (more than $20 \mathrm{KHz}$ ), is a widely accepted technique for flaw detection. Ultrasonic testing takes a leading role in product quality control inspection compared to other NDT methods for locating and characterizing subsurface defects in casting industry (Jack, 1996). Not withstanding the advantages of ultrasonic inspection there are problems in identifying defects such as porosity, inclusions and cracks.

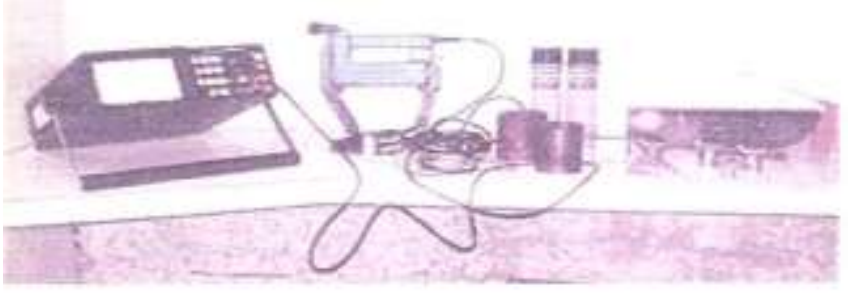

Fig 7.2 UTI

The ultrasonic inspection method requires a vast amount of knowledge and experience to properly establish inspection techniques and interpret results. The surface roughness of casting and their dimensional variations scatter the sound pulse and make detection of discontinuities difficult. The other major problem with ultrasonic inspection is associated with the grain size of the casting.

7.9.1 Procedure of inspection:

First calibrate the Ultrasonic machine with standard defect less sample and record the pulse propagation.

After calibration of Ultrasonic machine, we test the Hypoid pinion casting by arranging Ultrasonic machine and compare the pulse propagation with standard one. We can easily identify the defects location.

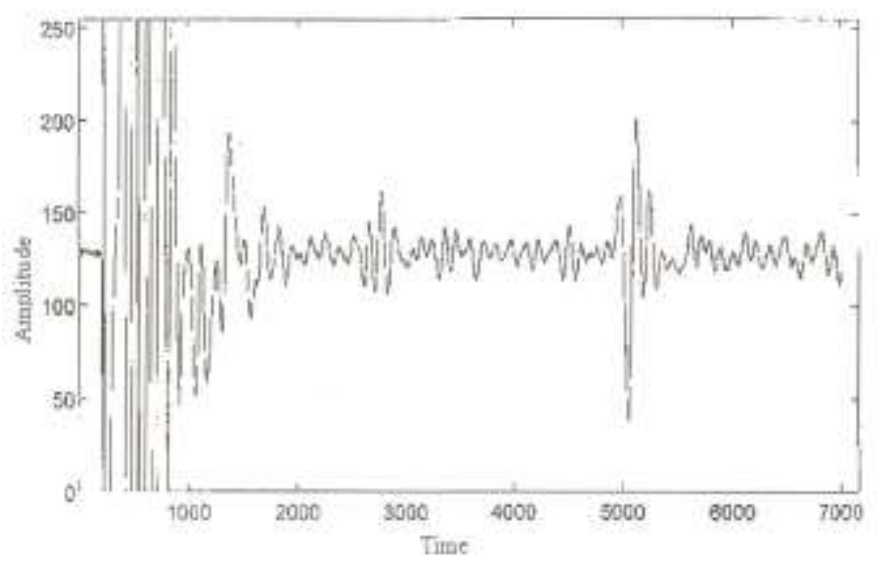

Fig 7.3 Pulses in UTI

\section{CASTING DEFECTS AND REMEDIAL ACTIONS}

Casting defects are significant: typically 1-10\% about 20 major types of casting defects: Flesh, mismatch, cold shut, misrun, blow hole, gas porosity, shrinkage cavity, porosity, centerline, sink, hot tear, crack, scab, swell, metal penetration, rough surface.

Other defects: improper composition and properties.

Minor defects can be repaired, with cost increase.

Major defects lead to rejection, with loss of productivity

\subsection{Different defects and their remedies:}

8.1.1 Metallic Projections

Joint flash or fins. Flat projection of irregular thickness, often with lacy edges, perpendicular to one of the faces of the casting. It occurs along the joint or parting line of the mould, at a core print, or wherever two elements of the mould intersect.

Possible Causes

Clearance between two elements of the mould or between mould and core;

Poorly fit mould joint.

Remedies

Care in pattern making, moulding and core making;

Control of their dimensions;

Care in core setting and mould assembly;

Sealing of joints where possible.

\subsubsection{Cavities}

Blowholes, pinholes. Smooth-walled cavities, essentially spherical, often not contacting the external casting surface (blowholes). The largest 
cavities are most often isolated; the smallest (pinholes) appear in groups of varying dimensions. In specific cases, the casting section can be strewn with blowholes of pinholes. The interior walls of blowholes and pinholes can be shiny, more or less oxidized or, in the case of casting iron, can be covered with a thin layer of graphite. The defect can appear in all regions of the casting.

\subsubsection{Possible Causes}

Blowholes and pinholes are produced because of gas entrapped in the metal during the course of solidification:

Excessive gas content in metal bath (charge materials, melting method, atmosphere, etc.); Dissolved gases are released during solidification; In the case of steel and cast irons: formation of carbon monoxide by the reaction of carbon and oxygen, presents as a gas or in oxide form. Blowholes from carbon monoxide may increase in size by diffusion of hydrogen or, less often, nitrogen;

Excessive moisture in moulds or cores;

Core binders which liberate large amounts of gas;

Excessive amounts of additives containing hydrocarbons;

Blacking and washes which tend to liberate too much gas;

Insufficient evacuation of air and gas from the mould cavity:- insufficient mould and core permeability;

Entrainment of air due to turbulence in the runner system.

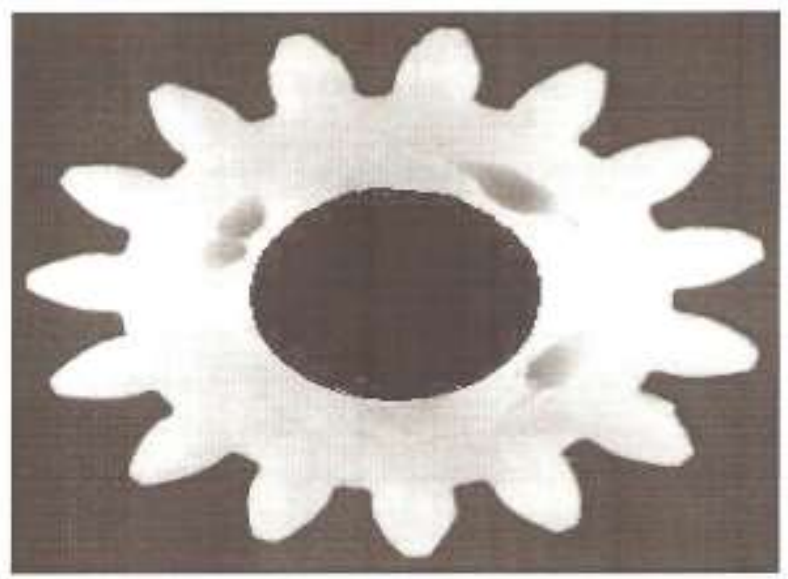

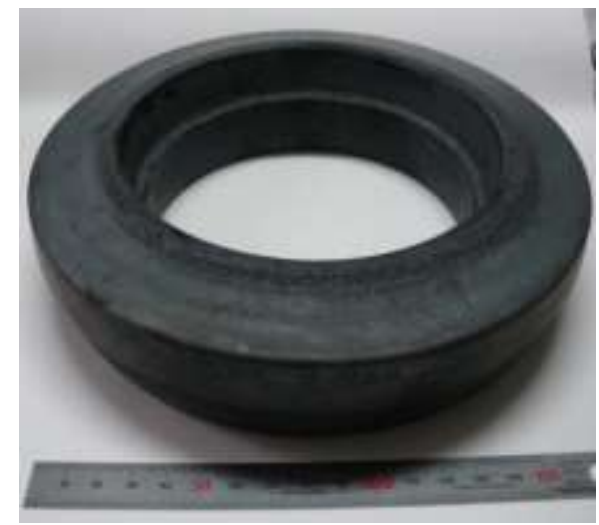

Fig 8.1

\subsubsection{Remedies}

Make adequate provision for evacuation of air and gas from the mould cavity;

Increase permeability of mould and cores;

Avoid improper gating system;

Assure adequate baking of dry sand moulds;

Control moisture levels in green sand moulding;

Reduce amount of binders and additives used or change to other types:- use blackings and washes, which provide a reducing atmosphere; -keep the spree filled and reduce pouring height;

Increase static pressure by enlarging runner height.

\subsubsection{Discontinuities}

Hot cracking. A crack often scarcely visible because the casting in general has not separated into fragments. The fracture surfaces may be discolored because of oxidation. The design of the casting is such that the crack would not be expected to result from constraints during cooling.

\subsubsection{Possible Causes}

Damage to the casting while hot due to rough handling or excessive temperature at shakeout

\subsubsection{Remedies}

Care in shakeout and in handling the casting while it is still hot;

Sufficient cooling of the casting in the mould;

For metallic moulds; delay knockout, assure mould alignment, use ejector pins.

\subsubsection{Defective Surface}

Flow marks. On the surfaces of otherwise sound casting, the defect appears as lines which trace the flow of the streams of liquid metal.

\subsubsection{Possible Causes}


Oxide films which lodge at the surface, partially marking the paths of metal flow through the mould.

\subsubsection{Remedies}

Increase mould temperature;

Lower the pouring temperature;

Modify gate size and location (for permanent moulding by gravity or low pressure);

Tilt the mould during pouring;

In die casting; vapor blast or sand blast mould surfaces which are perpendicular, or nearly perpendicular, to the mould parting line.

\subsubsection{Incomplete Casting}

Poured short. The upper portion of the casting is missing. The edges adjacent to the missing section are slightly rounded; all other counter conform to the pattern. The spree, risers and lateral vents are filled only to the same height above the parting line, as is the casting (contrary to what is observed in the case of defect).

\subsubsection{Possible Causes}

Insufficient quantity of liquid metal in the ladle;

Premature interruption of pouring due to workman's error.

\subsubsection{Remedies}

Have sufficient metal in the ladle to fill the mould; Check the gating system;

Instruct pouring crew and supervise pouring practice.

8.1.6 Incorrect dimensions or shape

Distorted casting. Inadequate thickness, extending over large areas of the cope or drag surfaces at the time the mould is rammed.

\subsubsection{Possible Causes}

Rigidity of the pattern or pattern plate is not sufficient to withstand the ramming pressure applied to the stand. The result is an elastic deformation of the pattern and a corresponding, permanent deformation of the mould cavity. In diagnosing the condition, the compare the surfaces of the pattern with those of the mould itself.

\subsubsection{Remedies}

Assure adequate rigidity of patterns and pattern plates, especially when squeeze pressures are being increased.
Metallic inclusions. Metallic or inter-metallic inclusions of various sizes which are distinctly different in structure and color from the base material, and most especially different in properties.

These defects most often appear after machining.

\subsubsection{Possible Causes}

Combinations formed as inter-metallic between the melt and metallic impurities (foreign impurities);

Charge materials or alloy additions which have not completely dissolved in the melt;

Exposed core wires or rods;

During solidification, insoluble inter-metallic compounds form and segregate, concentrating in the residual liquid.

\subsubsection{Remedies}

Assure that charge materials are clean; eliminate foreign metals;

Use small pieces of alloying material and master alloys in making up the charge;

Be sure that the bath is hot enough when making the additions;

Do not make addition too near to the time of pouring;

For nonferrous alloy, protect cast iron crucibles with a suitable wash coating.

\subsubsection{Cracks}

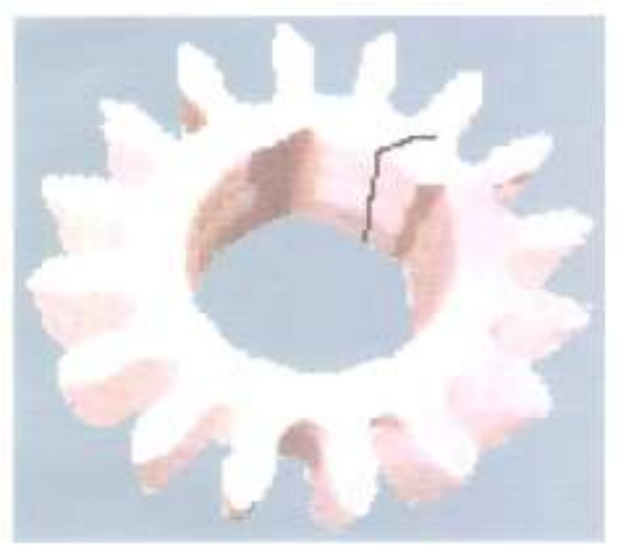

Fig 8.2

Reasons;

Non collapsibility of core.

Remedies

Increase the collapsibility of core by adding saw dust to core sand mixer 


\section{CONCLUSION}

We concluded that every firm should follow best economical manufacturing processes for producing sound castings and also used new modern technologies for increasing quality of casting in this competitive world.

Core setting is the most useful method of all production technology methods. The spectrometric analysis proved to be most useful for Hypoid pinion manufacture. All the defects are modified using most of the common techniques.

We also conclude that hypoid gear forging manufacturing process is better than casting process due to number of error is more than forging in casting. So we prefer forging operation.

\section{Acknowledgements}

We like to express our sincere gratitude and heart full thanks to the under stated persons for the successful completion of our project work.

First and foremost we wish to thank our guide Mr. Sanjeev assistant professor of CBS Group of Institution for his esteemed guidance, valuable advices and almost care at every stage of project. I would like to thank Mr. Arul Kumar, COO, SPICER INDIA PVT LIMITED

For providing me an opportunity to do our Practice School in Spicer India Pvt Ltd. I am also thankful to Mr. Manish Korde-(Plant head) for his encouragement.

I am grateful to my project guide Mr. P. Harinadarao for his direction during my research he helped steer me in the right direction and ensured that all necessary details has been care of . I would like to thank the all the members whose was of immense help in completing this project.

For direct or indirect help, we owe our sense of gratitude for the faculty of mechanical engineering section in CBS Group of institution and employees working in Spicer India Ltd-Pune.

\section{About Organization}

We have done our project in Dana Spicer India Pvt limited, Pune, India. It produces high quality and cost competitive Automobile vehicle Axle \& Hypoid Gear. It is ANAND Group of Company in Collaboration with Dana USA is the manufacturing of Axles for TELCO, M\&M,
FORD, HINDUSTAN MOTORS, MERCEDES BENZ \& GM. SPICER INDIA LTD (AXLE DIV) has achieved the following certificates of TS: 16949, QS: 9000, ISO 14001 \& OHSAS 18001 Company. Manufacture of Differential case, Carriers and Companion Flanges for domestic as sell as export.

\section{REFERENCES}

1. Production Technology - R.K. Jain

2. Production Engineering- P.G. Sharma

3. Work shop Technology- Hazera Chowdary

4. Directional Solidification- R. odawer

5. Gating technology in steel casting practice - R. Wlodawer

6. The formation cavities in castings- F.Roll

7. Manufacturing and Fabrication Technology- Zakria Baig 